\title{
Modified calcium from waste by product of crustaceans (polymesoda erosa) shell as alternative sunscreen materials
}

\begin{abstract}
The seafood processing industry is bringing in a lot of waste every year around the world. However, crustacean's residues contain valuable compounds such as calcium carbonate that could potentially be used as a sunscreen. Thus, Polymesoda erosa shells were discovered and calcium carbonate was synthesized for the use in dermal applications. The properties of Polymesoda erosa shells have been characterized by Fourier Transform Infrared Ray (FTIR) and Cytotoxicity tests. Emulsions were formulated and tested on Visible Ultraviolet (UVVis) Spectroscopy. The results showed the shells that were dissolved with $\mathrm{MnCl}_{2}$ portrayed a higher tendency to be sun-protective than $\mathrm{FeO}$ and the unmodified shell. Therefore, the use of waste from Polymesoda shells will not only add value to the by-products, but also help reduce environmental. Therefore, the formulation of emulsions synthesized from crustacean's shells is designed as a new hybrid in cosmetics products and improves the skin's protective efficacy against UV rays.
\end{abstract}

Keywords: biomaterials, calcium carbonate, crustaceans waste, Polymesoda erosa, sunscreen, sun protection, de-fluoridation, UV radiation, titanium dioxide, coral bleaching, copper tone, streptomycin, maxillofacial, iron, zinc oxide

\author{
Volume 8 Issue 5 - 2019
}

\author{
Mohd Zul Helmi Rozaini,' Md Uwaisulqarni \\ Osman, ${ }^{2}$ Mohd Hasmizam Razali, ${ }^{2}$ Chia Poh \\ Wai, ${ }^{2}$ Nor Hayati Ibrahim, ${ }^{3}$ Mohd Amir Fikri M \\ Fauzi $^{2}$ \\ 'Institute of marine biotechnology, universiti of Malaysia \\ terengganu, Malaysia \\ ${ }^{2}$ Department of science and marine environment, universiti of \\ Malaysia terengganu, Malaysia \\ ${ }^{3}$ Department of fisheries and food sciences, universiti of Malaysia \\ terengganu, Malaysia
}

Correspondence: Mohd Zul Helmi Rozaini, Institute of marine biotechnology, universiti of Malaysia terengganu, 21030 Kuala Nerus, Terengganu, Malaysia, Tel +6096685072 ,

Email zulhelmi@umt.edu.my

Received: September 16,2019 | Published: September 30, 2019
Abbreviations: UV, ultraviolet; FTIR, fourier transform infrared radiation; $\mathrm{KBr}$, potassium bromide; $\mathrm{TiO}_{2}$, titanium dioxide; FBS, fetal bovine serum; PBS, phosphate buffer saline; DMEM, dulbecco's modified eagle's medium; SPF, sun protection factor

\section{Introduction}

Most of commercial sunscreen nowadays promising effectiveness with broad protection range of UV light. The usage of sun block as additional barriers against illness and DNA damage by absorbing adverse ultraviolet (UV) ray is now to be a crucial issue. However, there have been huge concerns on commercial sunscreen regarding the environmental disturbances of marine organisms such as coral reefs and potential adverse of the inorganic materials. The various delicate and colorful coral reefs were destroyed and turned white while losing their attractiveness due to the bleaching. Over 3,500 sunscreen products worldwide such as L'Oreal, Coppertone, and Banana Boat were claimed that coral reefs was polluted and damaged by chemical ingredients which mostly obtained from swimmers who are wearing sunscreens. ${ }^{1}$ Recent research reported that the damaged of coral bleaching is caused by the excessive of oxybenzone substance which are contained in various sun block. ${ }^{2}$

Crustacean shells are of particular interest because of the abundance from sea food industry as process waste and environmental benefits associated with recycling them. It is estimated that $6-8$ million tons of shells are produced annually in the world and most of it is left to rot in the sea or is dumped as land-fill. Crustaceans shell came from kepah become waste with an abundance of calcium carbonate where it can be potentially used as alternative sunscreen. Crustaceans shell like crab and prawn had been studied for application such as defluoridation of drinking water and removal of $\mathrm{Cu}(\mathrm{II})$ ions. HAp has attracted a great deal of attention due to its high capacity for the removal of heavy metal ions, low water solubility, high stability under reducing and oxidizing conditions, availability and low cost. As kepah is easily can be obtained and cheap sources hence it can be used to produce sunscreen. ${ }^{3}$

Commonly, the sunscreen used nano size active ingredient to absorb ultraviolet (UV) radiation. They used nano zinc oxide $(\mathrm{ZnO})$ and nano titanium dioxide $\left(\mathrm{TiO}_{2}\right)$ in inorganic sunscreen in order to whiten the skins in a short period. ${ }^{4,5}$ However, the arising matter will be the consequences after being applied because the chemical ingredients may lead to severe effects such as skin cancer. Many people have concerns about it because the potential in treating the skin has becoming more harmful to the skin. Thus, sunscreen agent of $\mathrm{TiO}_{2}$ and $\mathrm{ZnO}$ can potentially replace with calcium carbonate; harmless sources of calcium derived from lime stones that effectually ingest the UV radiation. ${ }^{67}$ Calcium carbonate is usually used on damaged bone, implants and also filler specifically in cosmetics, biomedical applications, dental, maxillofacial and biomaterials. ${ }^{8,9}$ The physical structural of the bones is brittle properties, white color, and easier to get sources that provided abundance of HAp can turn into good carriers in sunscreen. ${ }^{10}$ It is also a promising candidate for advanced sunscreens. Furthermore, its UV absorption limit can be tuned to absorb in the desired range from UVB (290-320nm) to UVA (320$400 \mathrm{~nm}$ ) by simply introducing a metal doping.

Modifying the pure crustacean shell with suitable inorganic element will portrays an alternative sun block agent as novel organo- 
biomaterials. This also supported by the studies that reported that manganese and iron can enhanced the radiation compared to $\mathrm{ZnO}$ and $\mathrm{TiO}_{2}{ }^{7}$ Thus, this study was performed to synthesize and characterize the biomaterials from modified HAp with $\mathrm{Fe}$ and $\mathrm{Mn}$ from Polymesoda erosa shells as UV absorber. The shells were modified with in particular solution and multiphase materials obtained as alpha hematite and chloroapatite structures. The comparison between serum and manganese sunscreen agent were identified their effectiveness and without releasing dangerous radical under irradiation towards human and marine organisms.

\section{Material and methods}

\section{Sample storage and collection}

The Polymesoda erosa shell was collected from Sea Meq Industries, Tok Jiring, and Kuala Nerus. The shells were washed to ensure meats and fatty acids of its flesh are completely repelled from the shellac. The shells were then soaked in boiling water and keep replacing new water until clear water was formed. After the completion of washing process, the shells were kept in the freezer at $-20^{\circ} \mathrm{C}$ until further use. ${ }^{11}$

\section{Extraction of raw materials}

The shells were weighed with a mass of approximately $90 \mathrm{~g}$ using analytical balance before the addition of alkaline solution. The crustaceans shell was then divided into three beakers which contained of water, iron chloride (98\%, Merck) and manganese chloride $(98 \%$, Merck). Each of the samples in the beaker was heated at $70^{\circ} \mathrm{C}$ for three hours and stirred. $30 \mathrm{~mL}$ of $1.0 \mathrm{M}$ of ammonium hydroxide was added into the solution of $\mathrm{FeCl}_{2}$ and $\mathrm{MnCl}_{2}$ to reduce the acidity of solution until $\mathrm{pH}$ meter indicating $8.0 \mathrm{pH},{ }^{7}$ the shells were dried again an overnight in oven and calcined at $900^{\circ} \mathrm{C}$ for three hours in a furnace. The sample was then re-weighed with analytical balance to detect the potential mass loss from the evaporation process occurred. The calcined shells were converted by grinding into powder form with high-energy ball mill for 15 minutes at $450 \mathrm{rpm}$ to yield powder.

\section{Characterization of crustacean's shells}

Fourier transform infrared radiation (FTIR): Fourier Transform Infrared Radiation (FTIR) was examined by Perkin Elmer Spectrum 100 to determine the infrared spectrum of absorption of a solid. Samples of Polymesoda erosa shell powder was prepared by grinding the potassium bromide $(\mathrm{KBr})$ and well mixed with 1:6(HAp: $\mathrm{KBr})$ ratio. Then finely pulverized and put into a compressor. $\mathrm{KBr}$ becoming a disc shape with plastic-like when subjected to pressure and form a sheet that is transparent in the infrared region.

Cell culture: The $\mathrm{L} 6$ epitileum cell was grown at $37^{\circ} \mathrm{C}$ in $5 \%$ carbon dioxide atmosphere in Dulbecco's modified eagle's medium (DMEM) supplemented with $10 \%$ fetal bovine serum (FBS) and $1 \%$ antibiotic (penicillin streptomycin). Phosphate buffer saline (PBS) was prepared according to the manual given by the product. Each tablet of PBS need to be dissolved in $100 \mathrm{~mL}$ of distilled water and autoclave before storage in fridge until further use. In this study, the cell was admitted to grow to $80 \%$ to $90 \%$ confluence.

Initiating culture: The frozen cells were retrieved from liquid nitrogen tank and the cells were thawed in cryovial tube rapidly. The cells were quickly thawed by gently rubbing the vial between the palms of hands until there was just a small bit of ice left in the vial.
The vial was transferred into a laminar flow hood. Before opening the outside of the vial was wiped with $70 \%$ ethanol. The thawed cells were transferred into the centrifuge tube. Pre-warmed growth medium DMEM with $10 \%$ FBS and $1 \%$ penicillin streptomycin was added to the cells suspension in the tube. The cells suspension was transferred to centrifugation at $500 \mathrm{rpm}, 4^{\circ} \mathrm{C}$ for 1 minute. Then, supernatant were removed and another $10 \mathrm{~mL}$ of pre-warmed growth medium DMEM with $10 \%$ FBS and $1 \%$ penicillin streptomycin was added. Cells suspension was gently re-suspended to avoid any bubbles formation. Cell culture flask was prepared and cells suspension was transferred to the flask. For cells culture flask of $75 \mathrm{~cm}^{3}, 15 \mathrm{~mL}$ of growth medium were added and the solution was kept in incubator at $37^{\circ} \mathrm{C}, 5 \% \mathrm{CO}_{2}$ to incubate. The cells were kept in incubator for at least 24 hours without disturbance.

Maintenance of established cells: Cells were examined carefully for sign of contamination or deterioration. Old culture medium was removed. A volume of $5 \mathrm{~mL}$ PBS was added into the flask to wash the cells and discarded. $10 \mathrm{~mL}$ of complete medium was added into the flask. Cells were incubated at $37^{\circ} \mathrm{C}, 5 \% \mathrm{CO}_{2}$ in humidified incubator.

Cells counting: Haemocytometer was used to count the cells. Surface of haemocytometer was sprayed with disinfecting solution and wiped in clean and dry. $10 \mu 1$ of trypan blue dye was pipette on the surface of parafilm followed by $10 \mu 1$ of L6 cells suspension. Then, suspension was mixed homogenously by using pipette. The suspension then was transferred to the edge of haemocytometer chamber. The slide was observed under interved microscope. The number of viable cells (seen as bright cells) within the four corners squares were counted and recorded. Cells concentration was calculated using the following formula:

$$
\text { Cells concentration }(\text { cells } / m L)=((A+B+C+D) / 4) \times 2 \times 10^{4}
$$

Sunscreen analysis: The sunscreen analysis was determined to test the capability as sunscreen by in-vitro method using UV Visible spectrophotometer of UV 1700 Shimadzu. An amount of $1.0 \mathrm{~g}$ of each formulated micro emulsion samples was weighed and transferred into $100 \mathrm{~mL}$ of volumetric flask and then was diluted to the graduated mark with ethanol. The solution was homogenized by ultra sonicator for 5 minutes. The homogenized samples were filtered by filter paper and the first $10 \mathrm{~mL}$ of micro emulsion was expelled. A $5.0 \mathrm{~mL}$ of aliquot was transferred to $50 \mathrm{~mL}$ of volumetric flask and diluted to the graduated mark with ethanol. All the aliquot solution then was closed in the vials and was kept under dark condition at $25^{\circ} \mathrm{C}$.

\section{Results and discussion}

\section{Fourier transform infrared radiation (FTIR)}

FTIR test was conducted to HAp, HAp-Fe and HAp-Mn from Decapterus maruadsi bones. The results have showed most of the graph obtained broad signal over $3400 \mathrm{~cm}^{-1}$ and the long decline peaks were observed at $1000 \mathrm{~cm}^{-1}-1100 \mathrm{~cm}^{-1}$ as shown in Figure 1. The spectrum was recorded in the range of $4000-450 \mathrm{~cm}^{-1}$. The result has indicated that phosphate (PO) group was laid on $560-610 \mathrm{~cm}^{-1}$ and $900-1100 \mathrm{~cm}^{-}$ ${ }^{1}$. The band at $560-610 \mathrm{~cm}^{-1}$ corresponds to symmetric P-O stretching vibration of the $\mathrm{PO}_{4}$ group. As a major peak of phosphate group, the vibration peak could be identified in the region between 900-1100 $\mathrm{cm}^{-1}$ indicate to $\mathrm{P}-\mathrm{O}$ asymmetric stretching of $\mathrm{PO}_{4}^{3-}$. The bending 
mode of water $\left(\mathrm{H}_{2} 0\right)$ was detected at the range of $1600-1700 \mathrm{~cm}^{-1}$ where the water from shells was adsorbed. The presence of peak in the region $1400 \mathrm{~cm}^{-1}-1450 \mathrm{~cm}^{-1}$ that observed was due to absorbed carbon dioxide $\left(\mathrm{CO}_{2}\right){ }^{11,12}$ The band at $2000-2079 \mathrm{~cm}^{-1}$ is due to overtone of $1040 \mathrm{~cm}^{-1}$ band. The crystalline powder generates two characteristic stretching modes of $\mathrm{O}-\mathrm{H}$ bands at over $3000 \mathrm{~cm}^{-1}$ from calcium carbonate molecules. The combination of HAp compound with $\mathrm{Fe}$ has been detected and at the wave number $2950 \mathrm{~cm}^{-1}$ corresponds to $\mathrm{Ca}_{9} \mathrm{FeH}\left(\mathrm{PO}_{4}\right)_{7}$ because proton might present in carbonate. ${ }^{13}$ While the peak indicated on wave number $2810 \mathrm{~cm}^{-1}$ has shown it belongs to $\mathrm{Mn}_{5}\left(\mathrm{PO}_{4}\right)_{3} \mathrm{Cl}$ because the subatomic particles might present in the calcium carbonate.

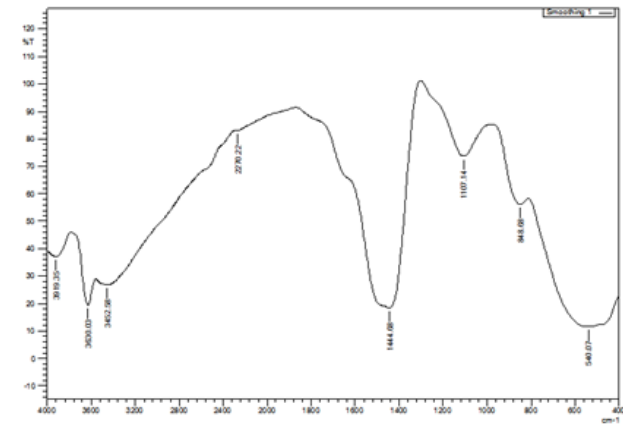

(A)

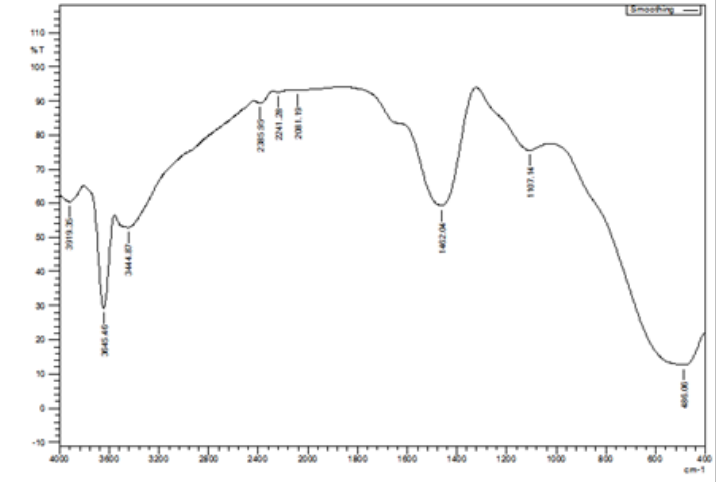

(B)

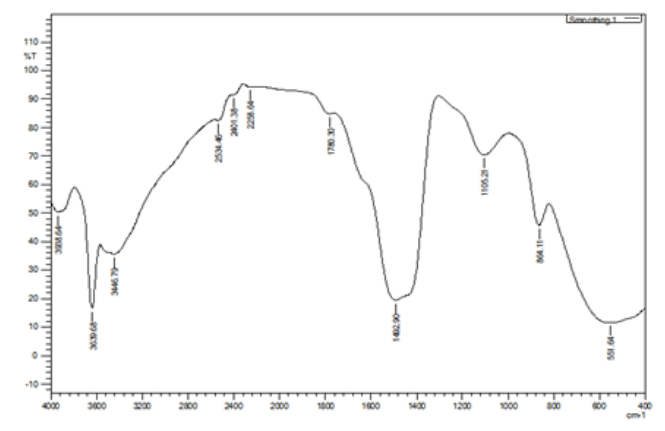

(C)

Figure I Results of FTIR analysis (a) pure Polymesoda erosa shells, (b) shellsFe and (c) shells-Mn.

\section{Cytotoxicity}

The cytotoxicity test was determined to identify the toxicology and risk valuation towards human skin, ${ }^{14}$ the cytotoxicity test was carried out to test viability cell on pure Polymesoda erosa shells, shells-Fe and shells and also standard emulsion using trypan blue dye against L6 cell lines. Each of the sample shown the percentage of viability increase until reaching over $100 \%$, Pure Polymesoda erosa shell indicates on the first lead, which it determined the viability of cell over $100 \%$ and followed by Shell-Fe at $100 \%$. While the percentage of viability for standard emulsion was at $95 \%$ and shells-Mn at $85 \%$. The graph shows the Inhibition Concentration, $\mathrm{IC}_{50}$ of the sample more than $30 \mu \mathrm{g} / \mathrm{ml}$ and means that all samples do not exhibit toxicity against L6 cell lines is shown in Figure 2.

\section{Cytotoxicity}

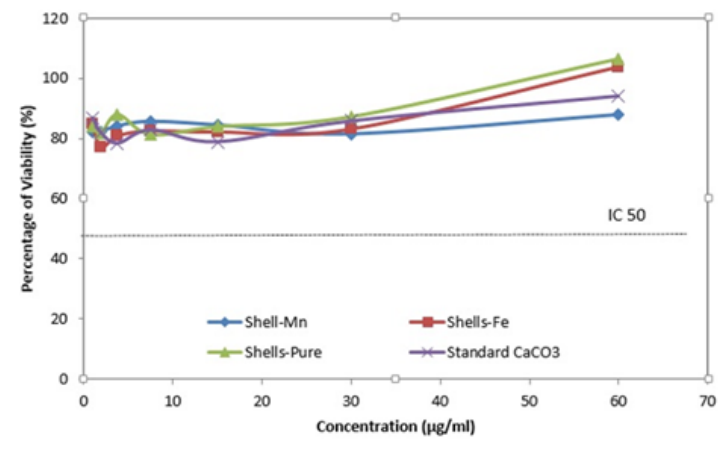

Figure $\mathbf{2}$ The cytotoxicity result of unmodified and modified shells emulsions within 24 hours using L6 cell lines.

\section{Sunscreen analysis}

The sunscreen analysis was conducted on standard emulsion (emulsion), emulsion with pure Polymesoda erosa shells (emulsion pure), emulsion of modified Polymesoda erosa shells with serum (emulsion shell-Fe) and emulsion of modified Polymesoda erosa with manganese (emulsion shell-Mn) and this study was applied the Mansur equation to determine the SPF values. The emulsion formulation was analyzed to obtain the SPF value and comparing which emulsions have high tendency as protector from direct UVrays. This is because the SPF is representing the effectiveness of a sunscreen formulation, ${ }^{15}$ the calculated SPF values on emulsion, pure Polymesoda erosa shells emulsion, emulsion shell-Fe and emulsion shell-Mn was recorded in Table 1. The result has shown that the SPF measurement for emulsion shell-Mn was $29.04 \pm 0.55$ which achieved nearly SPF 30 and this led to the emulsion performed as a good sunscreen absorber than other emulsions. The emulsion shell-Fe was shown that the SPF value was $26.38 \pm 0.49$. The SPF measurement of emulsion Shell-Fe was lower than emulsion shell-Mn because of the dependence on the type of metal attachment with the fish bones; with the manganese was claimed as having more potential in prevention of UV rays rather than serum. ${ }^{15,16}$

The SPF measurement of pure Polymesoda erosa shell emulsion was $19.49 \pm 0.65$. This is because the shell had not altered and that is the reason the measurement value of emulsion calcium carbonate was lower than combined with metal compounds. ${ }^{15}$ The emulsion 
was observed the SPF measurement was $18.11 \pm 0.60$. It means that the material of the standard emulsion itself has possibility to shield dangerous UV rays. Therefore, it was clearly seen that the emulsion shell-Mn was shown as a great sunscreen due to the high absorption value among the emulsion. The sequence of great sunscreen was followed with emulsion shell-Fe, pure Polymesoda shell emulsion and base emulsion. The capability of shell-Mn as a sunscreen was due to the fact that the morphology tests before and of its good stability from the combination of each component in emulsion.

Table I The sun protection factor (SPF) value for emulsions as Mean \pm SD $(n=3)$

\begin{tabular}{ll}
\hline Emulsion & Sun protection factor (SPF) \\
\hline Base Emulsion & $18.11 \pm 0.60$ \\
Emulsion pure shell & $19.49 \pm 0.65$ \\
Emulsion shell-Fe & $26.38 \pm 0.49$ \\
Emulsion shell-Mn & $29.04 \pm 0.55$ \\
\hline
\end{tabular}

\section{Conclusion}

The FTIR characterized the functional groups of modified calcium carbonate or crustaceans shell and proven that the attachment of $\mathrm{Fe}$ and $\mathrm{Mn}$ with shell respectively. The results also portrays that the major components such as the hydroxy formed are similar to the hydroxy compared with the cytotoxicity tests showing that the original and modified bio calcium carbonate substances (shell-Fe \& shell-Mn) are also non-toxic to L6 cells. The SPF of sunscreen emulsion contained of pure shell, shell-Mn and available commercial sunscreen emulsions from various productions by UV spectroscopy method. Pure crustaceans shells recorded with SPF 20 and modified shell-Mn doped measured with SPF 26. Modified shell-Mn emulsions were recorded with SPF 30 and the highest SPF value. The $\mathrm{Fe}^{3+}$ doped HAp has a promising potential to be applied as a good sunscreen due to the extremely biocompatibility of HAp combined with the $\mathrm{Fe}^{3+}$ ions.

\section{Acknowledgments}

The authors would like to thank the Ministry of Education Malaysia (MOE) for awarding the fundamental research project under the Niche Research Grant Scheme [(NRGS)/2015/53131/17] and Fundamental Research grants Scheme (FRGS 59423/STWN/2016). We also would like to thank all volunteers that have made this study possible.

\section{Conflicts of interest}

The author declares that there are no conflicts of interest.

\section{Funding}

None.

\section{References}

1. Downs CA, Kramarsky-Winter E, Segal R, et al. Toxicopathological Effects of the Sunscreen UV Filter, Oxybenzone (Benzophenone-3), on Coral Planulae and Cultured Primary Cells and Its Environmental Contamination in Hawaii and the U.S. Virgin Islands. Arch Environ Contam Toxicol. (2016;70(2):265-288.
2. Welch C. Do Sunscreens` Tiny Particles Harm Ocean Life in Big Ways? National Geographic News Article. 2015.

3. Wagutu AW, Machunda R, Jande YAC. Crustacean derived calcium phosphate systems: Application in defluoridation of drinking water in East African rift valley. J Hazard Mater. 2018;347:95-105.

4. Boutinguiza M, Pou JR Comesaña, Lusquiños F, et al. Biological hydroxyapatite obtained from fi sh bones. Materials Science \& Engineering C. 2012;32(3):478-486.

5. Lewicka ZA, Colvin VL. Photoactivity Tests of TiO2 and ZnO Sunscreen Ingredients. 2012;1413.

6. Araujo TS, Souza SO, Sousa EMB, et al. Production and Thermal Stability of Pure and Cr3+ - doped Hydroxyapatite. 2010;249:1-7.

7. Piccirillo C, Rocha C, Tobaldi DM, et al. Hydroxyapatite- $\mathrm{Fe}_{2} \mathrm{O}_{3}$ Based Material of Natural Origin as an Active Sunscreen Filter. J Mater Chem B. 2014;36(2):5999-6009.

8. Ferraro V, Carvlho AP, Santos MM, et al. Extraction of High Added Value Biological Compounds from Sardine, Sardine-Typefish and Mackerel Canning Residues-A review. Mat Sci Eng C-Mater. 2013;33(6):31113120 .

9. Wang C, Chang T, Shi L, et al. Seafood Processing By-Products: Collagen and Gelatin. Kim SK(editor). Trend and Applications. New York: Springer Science. 2013.

10. Springsteen R Yurek, M Frazier, KF Carr. Invitro measurement of sun protection factor of sunscreens by diffuse transmittance1. Analytica Chimica Acta. 1999;380:155-164.

11. Mohd Zul Helmi Rozaini, Habibah Hamzah, Nor Fazliyana Mahta, et al. Calcium Hydroxiapatite-Based Marine Origin: Novel Sunscreen Materials for Cosmeceutical Treatments. Oriental Journal of Chemistry. 2018;34(8):2207-2210.

12. Mondal S, Mondal B, Dey A, et al. Studies on Processing and Characterization of Hydroxyapatite Biomaterials from Different Bio Wastes. Journal of Minerals \& Materials Characterization \& Engineering. 2012;11(1):55-67.

13. Dondi M, Matteucci F, Cruciani G, et al. Pseudobrookite ceramic pigments:Crystal structural, optical and technological properties. Solid State Sciences. 2007;9(5):362-369.

14. Venkatesan J. Isolation and Characterization of Nano-Hydroxyapatite from Salmon Fish Bone. Materials (Basel). 2015;8(8):5426-5439.

15. Basiron Y. Palm Oil Production Through Sustainable Plantations. European Journal of Lipid Science and Technology. 2007;109(4):289_ 295.

16. Bazargan-Lari R, Zafarani HR, Bahrololoom ME, et al. Removal of $\mathrm{Cu}$ (II) ions from aqueous solutions by low-cost natural hydroxyapatite/ chitosan composite: Equilibrium, kinetic and thermodynamic studies. Journal of the Taiwan Institute of Chemical Engineers. 2014;45(4):16421648 . 